\title{
Trends in Nuclear Medicine in Developing Countries
}

\author{
Maurizio Dondi ${ }^{1,2}$, Ravi Kashyap ${ }^{1,2}$, Diana Paez ${ }^{1,2}$, Thomas Pascual ${ }^{1,2}$, John Zaknun ${ }^{1,2}$, Fernando Mut Bastos ${ }^{1,2}$, \\ and Yaroslav Pynda ${ }^{2}$ \\ ${ }^{I}$ Nuclear Medicine Section, International Atomic Energy Agency, Vienna, Austria; and ${ }^{2}$ Division of Human Health, International \\ Atomic Energy Agency, Vienna, Austria
}

This article describes trends in nuclear medicine in the developing world as noted by nuclear medicine professionals at the International Atomic Energy Agency (IAEA). The trends identified are based on data gathered from several sources, including information gathered through a database maintained by the IAEA; evaluation of country program frameworks of various IAEA Member States; personal interactions with representatives in the nuclear medicine field from different regions of the world; official proceedings and meeting reports of the IAEA; participation in numerous national, regional, and international conferences; discussions with the leadership of major professional societies; and relevant literature. The information presented in this article relied on both objective and subjective observations. The aims of this article were to reflect on recent developments in the specialty of nuclear medicine and to envision the directions in which it is progressing. These issues are examined in terms of dimensions of practice, growth, and educational and training needs in the field of nuclear medicine. This article will enable readers to gain perspective on the status of nuclear medicine practice, with a specific focus on the developing world, and to examine needs and trends arising from the observations.

Key Words: PET; SPECT; databases; trends

J Nucl Med 2011; 52:16S-23S

DOI: 10.2967/jnumed.111.089193

I and morbidity has taken place across the world. Chronic and noncommunicable diseases, especially cardiovascular disease and cancer, are now leading causes of mortality. Moreover, changes in lifestyle, increasing life expectancies, and corresponding increases in the aging population are bringing the developing world ever closer to the developed world in the incidence of health problems (1-3). In May 2010, the General Assembly of the United Nations adopted a resolution that seeks to halt the increasing trend for premature deaths from noncommunicable diseases worldwide (4), integrating chronic diseases into the Millennium Devel-

Received Feb. 14, 2011; revision accepted May 5, 2011.

For correspondence or reprints contact: Maurizio Dondi, Nuclear Medicine Section and Division of Human Health, International Atomic Energy Agency, Wagramerstrasse 5, 1400 Vienna, Austria.

E-mail: m.dondi@iaea.org

COPYRIGHT @ 2011 by the Society of Nuclear Medicine, Inc. opment Goals. Given these demographic changes and the rising impact of chronic diseases, such as cancer and cardiac disease, the role of nuclear medicine in disease management is becoming more salient, and its potential impact is no longer limited to any particular region of the world. Despite converging needs for nuclear medicine across the developed and developing worlds, there remain key differences between these arenas because of socioeconomic disparities and academic heterogeneity.

The International Atomic Energy Agency (IAEA; http:// www.iaea.org/) is an independent international organization that is related to the United Nations system and that had 151 Member States as of November 2010 (5). The organizational structure includes 6 departments. The Department of Nuclear Sciences and Applications helps countries use nuclear and isotopic techniques to promote sustainable development objectives in agriculture, human health, water resource management, marine environment, and industrial applications. The Human Health Program, aimed at facilitating capacity building in IAEA Member States to address health care needs, is overseen by the Division of Human Health. Within this division, the Nuclear Medicine Section (6) has the mission of enhancing the quality of practice of nuclear medicine for diagnosis and treatment. The Nuclear Medicine Section provides advice on establishing and operating nuclear medicine facilities and encourages appropriate use and quality management approaches for obtaining the best results from the practice of nuclear medicine. All of these goals are achieved through cooperation among the Member States, so that developing countries can benefit from the advice and transfer of knowledge provided by experts or consultants supported by the IAEA to help establish new nuclear medicine practices or improve or strengthen existing ones. This cooperation is addressed at the regional or interregional level. Regional cooperation leads to a better appreciation of sociotechnical practices.

During the past decade, nuclear medicine practice has evolved through remarkable advances in radiopharmacy, instrumentation, and information technology, all of which have had prominent roles in propelling its growth. Novel technologies, such as PET, PET/CT, and SPECT/CT, have revitalized the practice of nuclear medicine; it is expected that other hybrid modalities, such as PET/MRI, and the development of novel radiopharmaceuticals will provide 
additional impetus for new diagnostic and therapeutic applications, thereby further strengthening the specialty $(7,8)$. Improved instrumentation with reductions in scanning times and radiation doses administered to patients and improvements in image resolution have enabled more confident and efficient diagnosis while improving a department's workflow. There is a risk, however, that the rising costs connected with these recent developments will widen the gap in resources and infrastructure between more advanced and less privileged countries, jeopardizing the worldwide accessibility and sustainability of nuclear medicine.

To accomplish its mission to promote scientific cooperation and transfer of nuclear technologies to Member States for peaceful applications (9), the IAEA maintains accurate information (obtained from surveys based on voluntary participation) regarding the status of technology, facilities, human resources, and educational infrastructure in Member States. To guide available resources to their optimal use, it is important to understand trends in the specialty. This understanding provides the necessary dynamism and opportunity for amendments, which in turn ensure that initiatives that are undertaken fulfill their objectives. It appears that there are differences in the practice of nuclear medicine across the world because of heterogeneity in factors such as instrumentation, radiopharmaceuticals, and human resources.

The trends identified are based on objective and subjective data gathered mainly from the IAEA's sources and from relevant academic literature. The IAEA collects information about trends in nuclear medicine in several ways, including a database of nuclear medicine centers, prioritization of requests submitted by various Member States for support of nuclear medicine activities, feedback given by professionals in different regions of the world at various consultant meetings held at IAEA headquarters, official organizational proceedings and meeting reports, personal communications, input from leaders of major professional societies, and relevant literature. This article provides a discussion of the status of and trends in nuclear medicine arising from the observations, with a focus on the practice, growth, and educational aspects of the field in the developing world.

\section{NUCLEAR MEDICINE DATABASE}

A project called Nuclear Medicine Database was initiated in 2007 with the aim of gathering and maintaining updated information about the status of nuclear medicine practice around the world. A comprehensive questionnaire has been developed and sent to Member States for distribution to nuclear medicine centers in various countries. The questionnaire is used to obtain information about equipment, practices, human resources, and radiation protection issues at participating centers. Other relevant data, such as type and number of procedures performed and educational needs, are registered in the database as well. Nuclear medicine facilities in Member States are encouraged to voluntarily add data online to the database, which is maintained by the IAEA. Participating centers are then encouraged to update their submitted information on a yearly basis.

This database is available online (10) and is being updated on a regular basis with information provided to the IAEA by nuclear medicine centers or national or regional organizations. It represents the status of nuclear medicine in developing countries. However, the information received represents data from registered centers only, which might not necessarily represent all existing facilities or equipment within a country (11); nevertheless, the database provides useful insight.

The Nuclear Medicine Database is used as a primary tool for the collection of information about nuclear medicine practice. Careful evaluation of the information submitted by centers at different times allows the IAEA to discern emerging trends. Sharing this collated information while maintaining complete confidentiality about a center provides valuable insight into changes needed in initiatives at different stages of development and into how to shape interventions to improve the practice of nuclear medicine. The inferences presented here are drawn from the collation of all survey responses received from 602 centers in 99 IAEA Member States, with the exclusion of North America, western Europe, Australia, and Japan, for 2008, 2009, and 2010. The numbers of countries and centers per region that provided inputs for the data presented here are shown in Table 1. The numbers, although small, are representative of the developing world across all geographical regions.

\section{NUCLEAR MEDICINE IN THE DEVELOPING WORLD: ISSUES IN PRACTICE, GROWTH, AND EDUCATION}

\section{Practice}

The inferences presented here are drawn from information obtained to ascertain the extent and type of practice of nuclear medicine worldwide (excluding North America, western Europe, Australia, and Japan). Measured by the average number of cases per center, the practice of nuclear medicine showed a $15 \%$ increase in 2009 compared with 2008. The practice registered a decrease of $7 \%$ in 2010 compared with 2009 , although the number of cases per center was higher than that in 2008. The subjective inputs indicated that a temporary shortage of technetium supplies

TABLE 1

Nuclear Medicine (NM) Centers and Countries That Provided Inputs for Nuclear Medicine Database by Region

\begin{tabular}{lcc}
\hline & \multicolumn{2}{c}{ No. of: } \\
\cline { 2 - 3 } \multicolumn{1}{c}{ Region } & Countries & NM centers \\
\hline Africa & 25 & 57 \\
Latin America and Caribbean & 17 & 131 \\
Asia & 16 & 144 \\
Middle East & 14 & 70 \\
Eastern Europe and northern Asia & 27 & 200 \\
Total & 99 & 602 \\
\hline
\end{tabular}


and advancement in competing imaging modalities may have been responsible for this observed decline in usage (Fig. 1).

Annual assessments of the use of nuclear medicine techniques by body system indicated that about two-thirds of the practice was used to perform bone, thyroid, and renal scans. Bone scans accounted for $25 \%-28 \%$ of all procedures performed over the 3 -y period and remained the most widely used application of nuclear medicine worldwide. Thyroid scans (accounting for almost the total figure in the endocrine category) ranked in second place, but the use of nuclear medicine for this purpose decreased by 8 percentage points from $24 \%$ of all cases in 2008 to $16 \%$ in 2010 (Table 2). Remarkably, renal scans (in the genitourinary category) ranked in third place (16\%-17\%), as they remain widely applied in the developing world, probably reflecting the lack of more sophisticated investigational means. Cardiovascular applications, which account for the highest percentage of all nuclear medicine procedures performed in the United States, ranked in fourth place, and in 2010 they represented only about $12 \%-13 \%$ of the overall nuclear medicine practice in the developing world. Nuclear imaging of the central nervous system continues to draw the least interest in the practice despite its noted merits, probably because of improved MRI techniques and inadequate training of professionals in the field. There was a sustained interest in therapeutic applications of nuclear medicine across all $3 \mathrm{y}$, and there was also a systematic increase in the use of PET in overall nuclear medicine practice (Table 2).

Table 2 also shows that despite an overall decrease in the number of nuclear medicine procedures performed per center in 2010, increases in the use of PET and, to a more limited extent, therapeutic applications of nuclear medicine were witnessed between 2008 and 2010. Interestingly, there was a striking increase $(>100 \%)$ in the use of PET every

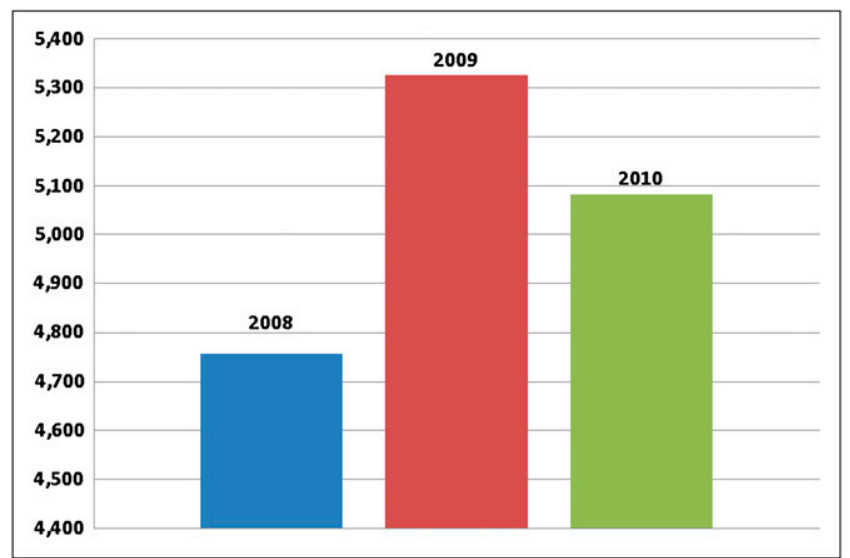

FIGURE 1. Trends in overall numbers of nuclear medicine procedures performed (average per center; shown on $y$-axis) in developing world (data from North America, western Europe, Australia, and Japan are not included). Decrease in 2010 relative to 2009 most likely was due to technetium shortage (see text). year from 2008 to 2010. Similarly, there was a steady increase $(25 \%)$ in the absolute numbers of therapeutic applications performed in 2009 compared with 2008, and there was a 12\% increase in 2010 compared with 2009.

\section{Growth}

A detailed evaluation of the growth of nuclear medicine across countries and regions indicates that practice has shown both homogeneous and heterogeneous trends across the world. Although the increase in therapeutic applications of nuclear medicine indicated some degree of homogeneity in all regions, the use of PET increased markedly in Asia and eastern Europe but only moderately in Latin America. The use of PET decreased markedly in the Middle East but remained stable in Africa (Fig. 2). The unusual trend in the Middle East, where nuclear medicine practice is usually supported by expatriates, seems to be related to a transient lack of adequate human resources and merits monitoring. In Africa, PET activity is limited largely to South Africa, where lack of reimbursement remains an issue; however, countries along the Mediterranean rim are actively pursuing the introduction of this technology into their health care systems. As is well known, the performance of imaging equipment, an important component of overall nuclear medicine service, usually declines with prolonged use.

Both planar cameras and SPECT are in use worldwide. The present data indicate that the average equipment age is beyond $6 \mathrm{y}$ for all types of cameras in all regions of the developing world (Table 3). Africa and the Middle East lead in average equipment age for SPECT cameras, whereas prolonged use of planar cameras is noted in Latin America, the Caribbean region, eastern Europe, and northern Asia, with some systems in use for more than $30 \mathrm{y}$. This prolonged use of planar instrumentation often goes beyond the obsolescence period, and in many cases analog cameras are still in use. This factor may account for the types of nuclear medicine services offered in these regions and for the difficulties in effective performance.

Particularly relevant are the relatively low number of cardiac procedures and their decrease over the 3 surveyed years. This decrease was not homogeneous across all regions (Fig. 3). For example, a decrease was not seen in eastern Europe, where the use of these procedures remained unchanged, and the use of these procedures remained quite limited in Africa. The decline, however, was quite steep in Latin America, where a decline of $40 \%$ was seen in 2010 compared with 2008, and in Asia, where a decline of $30 \%$ was seen in 2010 compared with 2009.

One possible explanation is the technetium shortage that followed the disruption of irradiation services from a few large and aging research reactors. This shortage posed a serious challenge to the molybdenum supply chain in 2008 , resulting in a shortage in the availability of ${ }^{99 \mathrm{~m}} \mathrm{Tc}$ for the practice of nuclear medicine. Reductions in nuclear medicine services because of this shortage were reported to be at their maximum toward the end of 2009 and early 2010. 
TABLE 2

Use of Nuclear Medicine for Various Systems Worldwide in 2008, 2009, and 2010

\begin{tabular}{ccccccccccccc}
\hline & \multicolumn{10}{c}{ Procedures (\% of total) } \\
\cline { 2 - 12 } Year & CV & END & GI & GU & ONC & CNS & PUL & SKE & PET & MISC & THER \\
\hline 2008 & 12.38 & 24.20 & 3.74 & 17.86 & 2.77 & 1.16 & 4.46 & 25.41 & 0.69 & 2.94 & 4.39 \\
2009 & 13.01 & 18.75 & 4.07 & 16.15 & 3.42 & 1.17 & 4.35 & 27.90 & 3.94 & 2.55 & 4.69 \\
2010 & 12.05 & 15.63 & 3.74 & 16.67 & 3.22 & 1.02 & 3.30 & 28.30 & 8.14 & 2.49 & 5.44
\end{tabular}

$\mathrm{CV}=$ cardiovascular; END = endocrine; GI = gastrointestinal; GU = genitourinary; ONC = oncology (excluding bone scans and PET); CNS = central nervous system; PUL = pulmonary; SKE = skeletal; MISC = miscellaneous; THER = therapy.

Data from western Europe, North America, Australia, and Japan are not included.

This crisis had a noticeable impact on science and commerce related to technetium radiopharmaceuticals (12).

The relative increases in PET and therapeutic procedures may reflect not only the growing interest in the technology throughout the medical community but also the fact that the technology remained largely unaffected by the ${ }^{99 \mathrm{~m}} \mathrm{Tc}$ shortage because it does not require ${ }^{99 \mathrm{~m}} \mathrm{Tc}$. The use of compounds other than ${ }^{99 \mathrm{~m}}$ Tc-labeled radiopharmaceuticals may also explain the stability in the numbers of oncology procedures that did not include (in our database) bone scans, which are typically performed with ${ }^{99 \mathrm{~m}}$ Tc-labeled compounds.

One of the challenges that may hamper the growth of nuclear medicine practice in the developing world is the ability of nuclear medicine facilities to respond to the needs of referring clinicians. This factor, in turn, has consequences for the level of acceptance of the practice by clinical practitioners and for the overall development of the practice. Indeed, in regions such as Africa, ${ }^{99 \mathrm{~m}} \mathrm{Tc}$ generators may be received on a fortnight basis, and the ability to respond to requests therefore may be compromised for several days every month. From responses provided to the question about this topic, it appears that as many as $41 \%$

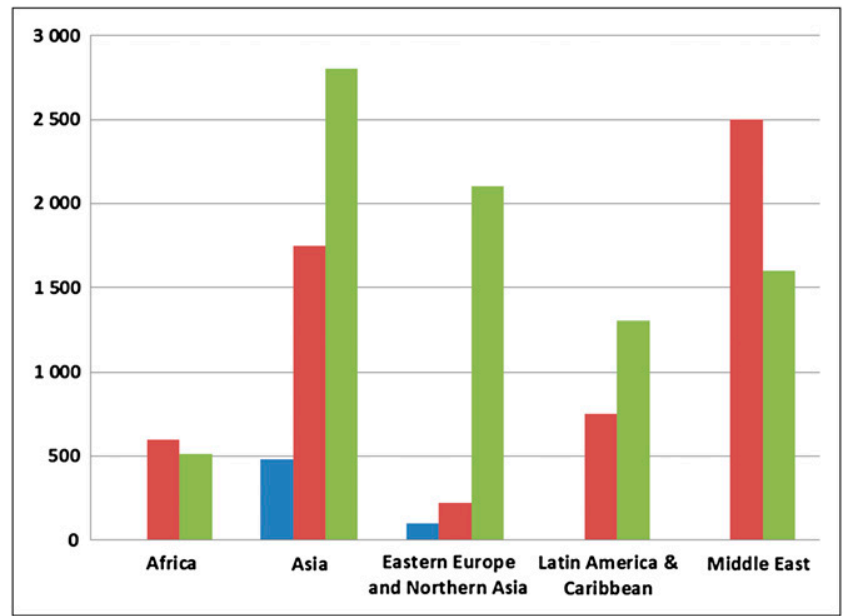

FIGURE 2. Trends in average numbers of PET procedures performed (shown on $y$-axis) per center in 2008 (blue bars), 2009 (red bars), and 2010 (green bars) by region. of centers worldwide believe that they are not responding adequately to needs (Fig. 4A), but the responses to this question varied from region to region. The lowest departmental efficiency is noted in Latin America and Africa, whereas maximal efficiency is noted in Asia (Fig. 4B). These findings may reflect the aging equipment in use in the former regions.

The questionnaire attempted to elicit responses to questions about why centers believed that they were not performing effectively (Fig. 5). The main reasons, in order of importance, appeared to be a lack of up-to-date or sufficient equipment, a lack of education or training, difficulties with supplies of radioisotopes and radiopharmaceuticals, and insufficient human resources. These findings are contrary to the popular notion held by many in the field of nuclear medicine that the practice is overregulated and that this overregulation hampers the delivery of nuclear medicine services. This notion is not substantiated by the data that we have collected: regulations were at the bottom of the list of elements adversely affecting nuclear medicine practice; only $5 \%$ of centers listed regulations as a possible reason for not performing effectively.

\section{Education and Training}

Nuclear medicine education and training curricula have undergone a significant transformation, from 1-2 wk of postgraduate teaching limited to preclinical and clinical training courses to a full postgraduate training program with a duration of 2-5 y. Curricular changes are being considered because they not only reflect technologic advan-

TABLE 3

Equipment Age by Region

\begin{tabular}{lcc}
\hline \multirow{1}{c}{ Region } & \multicolumn{2}{c}{$\begin{array}{c}\text { Average age of } \\
\text { equipment }(\mathrm{y})\end{array}$} \\
\cline { 2 - 3 } & $\begin{array}{c}\text { Planar camera } \\
\text { SPECT }\end{array}$ \\
\hline Africa & 12 & 9 \\
\hline Latin America and Caribbean & 21 & 7 \\
Asia & 12 & 7 \\
Middle East & 13 & 10 \\
\hline Eastern Europe and northern Asia & 19 & 6 \\
\hline
\end{tabular}




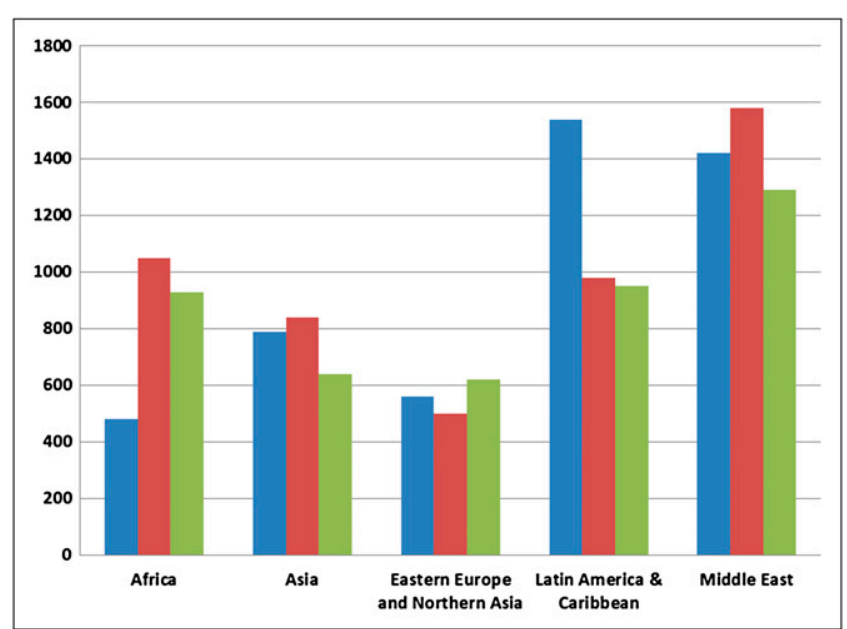

FIGURE 3. Trends in average numbers of myocardial perfusion imaging procedures performed (shown on $y$-axis) per center in 2008 (blue bars), 2009 (red bars), and 2010 (green bars) by region.

ces but also include the necessary emerging clinical competencies (13). Large nuclear medicine organizations in developed countries, such as the Society of Nuclear Medicine, the European Association of Nuclear Medicine, and the British Nuclear Medicine Society, provide exceptional training courses and publish guidelines and procedures to provide lifelong learning opportunities to their members. Such strong educational platforms and stringent requirements are in place to ensure that nuclear medicine professionals are adequately trained to provide patients with optimal and safe care (14).

However, these ideal types of structured, highly supported mechanisms for nuclear medicine training for physicians are accessible mostly in the developed world, where there is good support from governments, national organizations, and the industry. In the developing world, several factors may directly hamper nuclear medicine training for physicians. Legislative hurdles, limited human resources, and health care system restrictions limit easy access to basic nuclear medicine technology and newer developments in the field, such as PET/CT (15). An interplay of these factors widens the gap between developed and developing countries' access to standard and advanced nuclear medicine knowledge.

Nuclear medicine and radiology have witnessed significant changes in technology in recent years, particularly with the introduction of hybrid imaging devices. These changes have led to the consideration of cross-training of physicians with nuclear medicine and radiology backgrounds. A revamping of training and residency programs by regional, national, and international initiatives is required to ensure a supply of imaging experts with skills in multiple modalities.

Regional differences or diversity in content, structure, and duration of training programs in nuclear medicine can be observed in the developing world. In some countries with existing nuclear medicine residency programs, there is no standardized syllabus for training. Pathways to postgraduate nuclear medicine training usually include entry into an academic or university program leading to a degree (such as Master in Science or Master of Philosophy) or a professional program. Some countries, such as Argentina, Bangladesh, Brazil, Colombia, Cuba, Chile, Egypt, India, Malaysia, Mexico, Pakistan, and South Africa, typically follow this type of training scheme, in which an academic program leading to a degree includes entrance into a structured training program within a university and concurrent involvement in a clinical setting, such as a hospital. The duration of training can vary from $2 \mathrm{y}$ to $5 \mathrm{y}$, depending on the program. Training usually leads to a degree in nuclear medicine such as Diploma, Master in Science, Master of Philosophy, Master of Medicine, or Doctor of Medicine, which qualifies the student to take a board examination, if applicable. The other pathway involves professional training in nuclear medicine; prospective trainees enter a 2- to 4-y residency training program (depending on previous qualifications) within an accredited training hospital approved by the government and professional bodies with or without university linkages. This type of program does not lead to an academic degree but, if applicable, would enable the candidate to pursue specialty board certification in his or her respective country after the completion of training. This scheme is typically patterned after the U.S. model for specialist training in nuclear medicine and can be observed in developing countries such as Algeria, the Philippines, Brazil, Chile, Colombia, Mexico, Peru, and Uruguay.

A recurring issue is that availability and diversity in the structure, duration, and implementation of nuclear medicine training programs in the context of the developing world can have several consequences for the practice of nuclear medicine. A contextual setting includes the availability of infrastructure and technologies, such as SPECT/ CT and PET/CT, that can be used to meet the clinical needs of the country and for training.

The present evaluation indicates heterogeneity in the training needs of various regions (Table 4). The leading areas requiring training in Africa are cardiology, applications of SPECT, quality management, and therapeutic nuclear medicine, whereas those in Asia are PET, quality management, receptor imaging, and neuropsychiatry.

Most developing countries lack specific training programs for nuclear medicine professionals, including physicians, physicists, radiopharmacists, and technologists. For the existing work force of nuclear medicine practitioners, there is a need for continuing medical education, particularly in new technologies, such as hybrid modalities, as well as for a more comprehensive understanding of some clinical applications, such as pediatrics. Among the various staff worldwide engaged in nuclear medicine, technologists lead in having the maximum need for training.

Moreover, both socioeconomic disparities and academic heterogeneity have resulted in unbalanced development in 


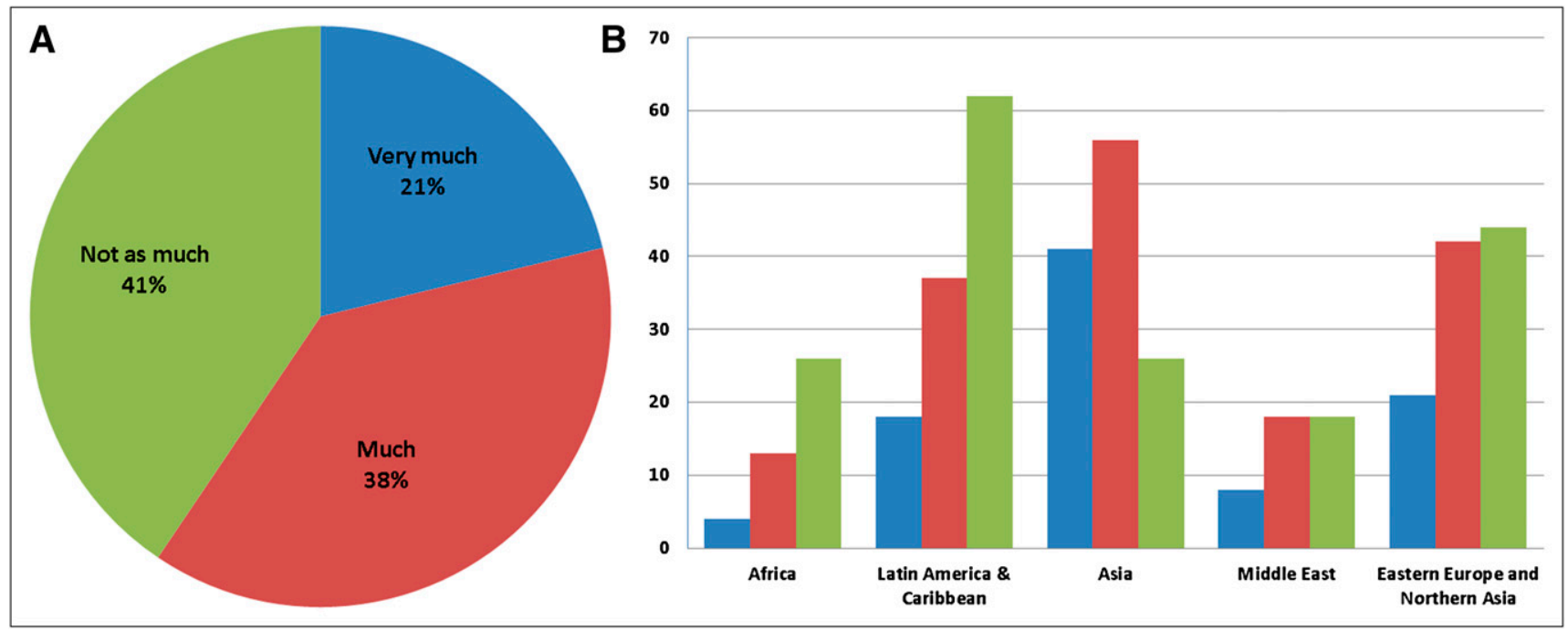

FIGURE 4. Departmental efficiency depicted worldwide $(A)$ and by region (B; values on $y$-axis are percentages) as perceived by participating centers. Participants were asked to rate efficiency of their departments in responding to requests from referring physicians as "very much" (i.e., highly efficient [blue bars]), "much" (i.e., efficient [red bars]), or "not as much" (i.e., not efficient [green bars]).

infrastructure, resulting in a wide range of unmet needs across the world. There are middle-income countries with strong academic centers equipped with top-of-the-line scanners comparable to those available in the developed world, emerging countries with the ability to fulfill only basic care needs, and several underdeveloped countries with no nuclear medicine infrastructure or a markedly outdated infrastructure.

The lack of existing training programs for nuclear medicine specialists or an organized regulatory body to oversee training can also be an issue, as can the lack of availability of fellowships or advanced training programs in nuclear medicine, such as those for nuclear cardiology, therapy, pediatric nuclear medicine, and PET/CT. In such situations, students must obtain training in neighboring middle-income or developed countries independently, a process that can be expensive and complex, or with the assistance of governments and organizations such as the IAEA (see more on this topic later in the article).

\section{ACTION PLAN WITH IAEA}

The IAEA is committed to helping Member States improve the use of nuclear medicine applications for diagnosis and treatment in health care. Monitoring of trends helps in prioritizing actions to increase and improve nuclear medicine practice. The actions are coordinated by the Nuclear Medicine Section in the Division of Human Health, which is part of the Department of Nuclear Sciences and Applications in the IAEA. The mechanisms of delivery are technical cooperation (16) and regular budget activities (17). Through national, regional, or interregional technical cooperation projects, Member States engage in the development of nuclear medicine in their countries.
The Nuclear Medicine Section is currently managing about 130 technical cooperation projects through which advice is provided on equipment, human resource development, and augmentation of the practice of nuclear medicine. The IAEA facilitates education and training by supporting fellowships, scientific visits, and expert missions. An review of activities that have taken place in the last $50 \mathrm{y}$ shows that the IAEA has supported more than 2,500 fellowships to train nuclear medicine professionals from developing countries for periods varying from a few months to 3-4 y. The total figure for training supported by the Agency for all nuclear medicine professionals over the last $50 \mathrm{y}$ adds up to $950 \mathrm{y}$, almost 1 millennium. In addition, more than 300 regional training courses have been organized in various regions in the last $20 \mathrm{y}$ for nearly 5,000 participants. In selected cases, for the least developed coun-

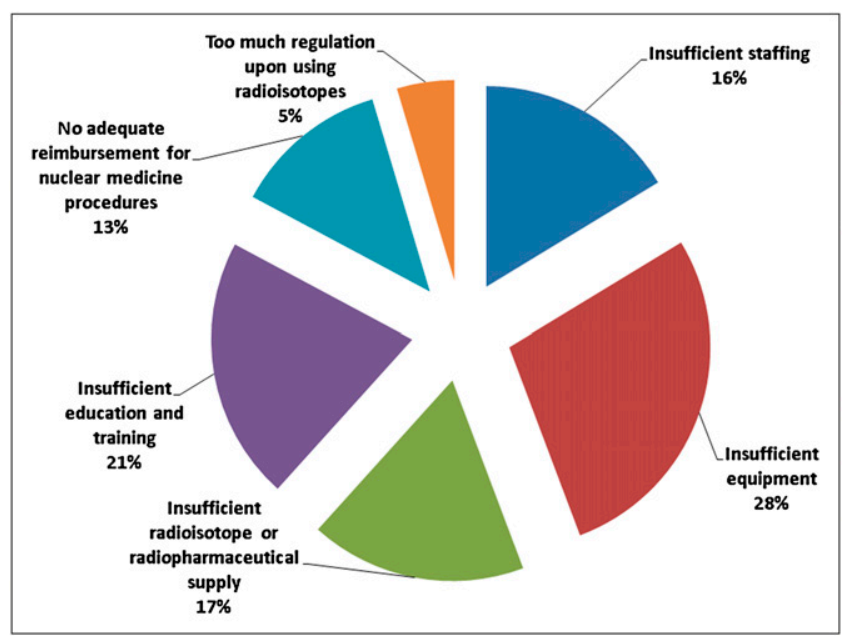

FIGURE 5. Relevant reasons for not performing effectively, as indicated by survey responses of participants. 


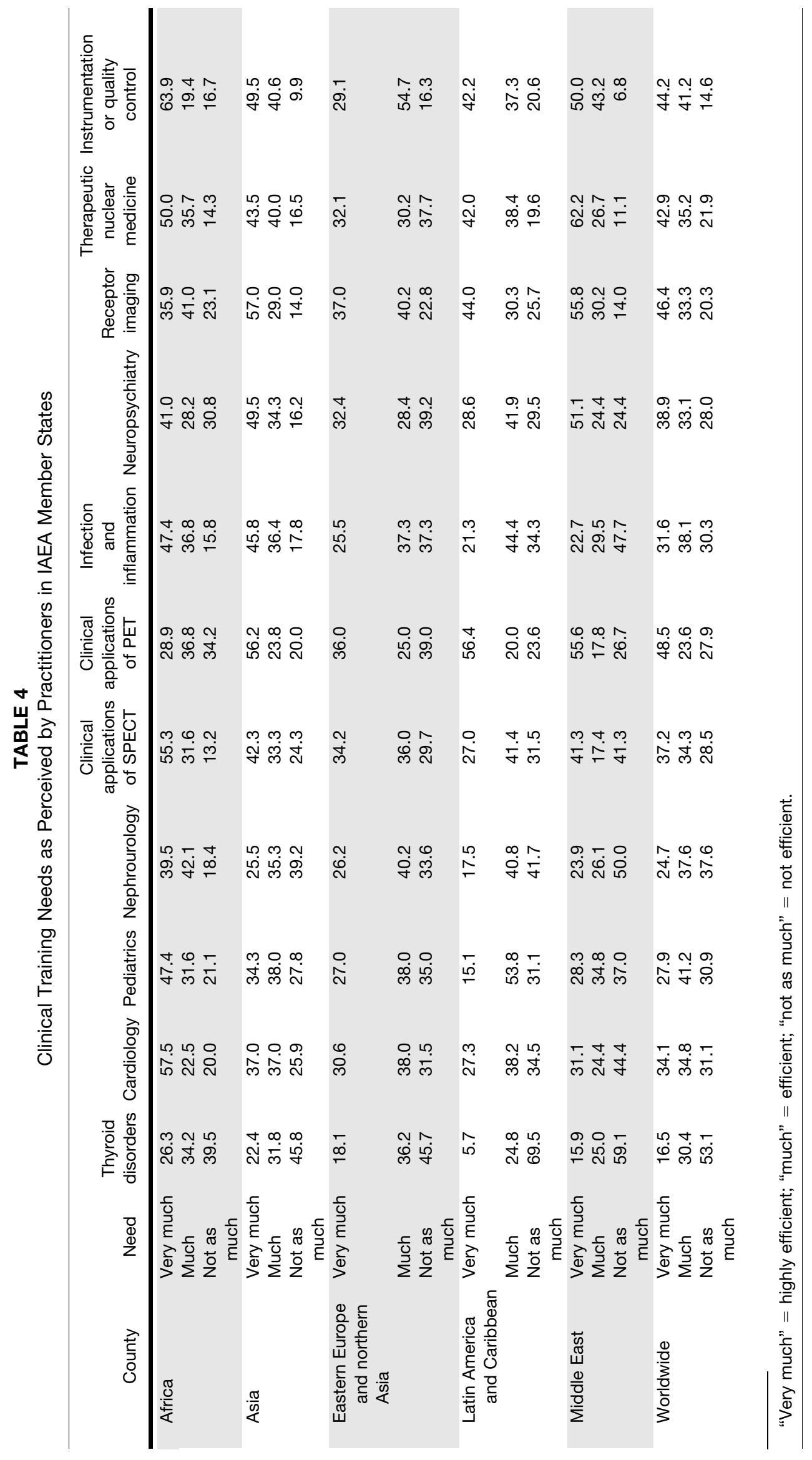


tries, the IAEA also supports the procurement of machinery such as double-head SPECT cameras (50 procured in the last $10 \mathrm{y}$ ), laminar flow hoods, dose calibrators, and all of the ancillary equipment needed to efficiently run a nuclear medicine facility. As a start-up provision, the IAEA also supplies generators and cold kits for a limited period of time. Participation in coordinated research projects of the IAEA also aids in the development of nuclear medicine practice and the establishment of a network of professionals engaged in this discipline. Every year, the Nuclear Medicine Section offers an average of 8-10 coordinated research projects on different topics of interest for Member States, from nuclear cardiology to therapy and PET applications.

On the basis of current trends, the IAEA intends to continue focusing on the fastest growing and most commonly used areas of nuclear medicine. Every effort is undertaken to standardize the assistance to benefit all regions. Consideration is given to accommodate the diverse needs of various regions of the world. The approach is to provide appropriate advice on equipment and facilities as well as to build capacity through quality management and education. Regional training courses, a distance assisted training program (18), and a human health campus (19) an educational Web site of the IAEA - are some of the key mechanisms of education. To achieve better outreach, the IAEA will continue partnerships with international organizations and societies to support education, training, and development for the field of nuclear medicine.

\section{CONCLUSION}

Expanding nuclear medicine practice and making it more responsive to emerging needs in chronic disease management remain strategic assets for the sustainability of the specialty worldwide. On the basis of trends in nuclear medicine in emerging countries, it appears that a strategy involving the customization of initiatives to meet regional needs for practice, growth, and education is appropriate. The main elements of the discordance between the needs and the current capacities of nuclear medicine centers are insufficient or obsolescent equipment and lack of education and training. Special attention must be given to maximizing the use of key applications, such as nuclear cardiology and PET, along with monitoring trends in practice. Attention to quality management and instrumentation is addressed by the departments participating in the database in most of the regions. The trends indicate that training in Asia requires a greater emphasis on PET applications, whereas training in
Africa requires more attention on SPECT. Overall, efforts need to be focused on the most commonly used and fastest growing areas in the discipline of nuclear medicine. International cooperation can help in the evolution of an enhancement strategy to improve the level of use and the quality of nuclear medicine in emerging countries.

\section{REFERENCES}

1. World Health Organization. The World Health Report 2008: Primary Health Care Now More Than Ever. Geneva, Switzerland: World Health Organization; 2008.

2. World Health Organization Media Centre. Cancer: fact sheet no. 297. Available at: http://www.who.int/mediacentre/factsheets/fs297/en/index.html. Published February 2011. Accessed July 13, 2011.

3. PAHO plan of action for cancer prevention and control: cancer stakeholders meeting (Washington, DC, 11-12 June 2008). Fact sheet: Cancer in Latin America and the Caribbean. Available at: http://www.paho.org/english/ad/dpc/nc/pccfact-sheet-LAC.pdf. Accessed July 13, 2011.

4. United Nations General Assembly. Agenda of the sixty-fourth session of the General Assembly, agenda item 114. Available at: http://www.un.org/ga/ search/view_doc.asp?symbol=A/64/251. Published September 18, 2009. Accessed July 13, 2011.

5. Member states of the IAEA. International Atomic Energy Agency Web site. Available at: http://www.iaea.org/About/Policy/MemberStates/. Updated July 21, 2011. Accessed July 21, 2011.

6. Nuclear medicine. International Atomic Energy Agency Web site. Available at: http://www-naweb.iaea.org/nahu/nm/default.asp. Updated November 2, 2001. Accessed July 21, 2011.

7. Patton JA, Townsend DW, Hutton BF. Hybrid imaging technology: from dreams and vision to clinical devices. Semin Nucl Med. 2009;39:247-263.

8. Hricak H, Choi BI, Scott AM, et al. Global trends in hybrid imaging. Radiology. 2010;257:498-506.

9. Dondi M, Andreo P. Developing nuclear medicine in developing countries: IAEA's possible mission. Eur J Nucl Med Mol Imaging. 2006;33:514-515.

10. NUMDAB (NUclear Medicine DAtaBase). International Atomic Energy Agency Web site. Available at: http://nucmedicine.iaea.org/. Accessed July 21, 2011

11. International Atomic Energy Agency. IAEA NUMDAB: taking the pulse of nuclear medicine worldwide. J Nucl Med. 2009;50(5):16N.

12. Esarey S. IAEA helps to close radioisotope production gap: vitally important diagnostic isotope used nearly once a second worldwide. IAEA Division of Public Information, International Atomic Energy Agency Web site. Available at: http://www.iaea.org/newscenter/news/2011/prodgap.html. Published January 7, 2011. Accessed July 13, 2011.

13. Graham M, Metter M. Evolution of nuclear medicine training: past, present, and future. J Nucl Med. 2007;48:257-268.

14. SNM Board of Directors. Competency in nuclear medicine. J Nucl Med. 2010;51 (10): $13 \mathrm{~N}$.

15. Gholamrezanezhad A, Mirpour S, Akhavan Behbahani A. Nuclear medicine in developing countries: perspective from Iran. J Nucl Med. 2010;51:14N-22N.

16. Department of Technical Cooperation. International Atomic Energy Agency Web site. Available at: http://tc.iaea.org/tcweb/default.asp. Accessed July 21, 2011.

17. Department of Nuclear Sciences and Applications. International Atomic Energy Agency Web site. Available at: http://www-naweb.iaea.org/na/. Accessed July $21,2011$.

18. Welcome to DATOL (DAT on-line). Distance assisted training for nuclear medicine professionals Web site. Available at: http://www.datnmt.org/. Accessed July $21,2011$.

19. IAEA Human Health Campus Web site. Available at: http://humanhealth.iaea. org. Accessed July 21, 2011. 